UDC: 821.134.2.09 Wencwslao Ayguals I. de DOI: https://doi.org/10.18485/hispserb.2019.2.ch13

\author{
Snežana Jovanović ${ }^{1}$ \\ Universidad de Kragujevac \\ Serbia
}

\title{
LA FICCIÓN LITERARIA Y EL MATERIAL EXTRALITERARIO DE LA NOVELA POPULAR: EL CASO DE AYGUALS DE IZCO
}

\begin{abstract}
Resumen
En el presente trabajo nos proponemos abordar uno de los rasgos predominantes de las novelas híbridas de Ayguals de Izco: el amplio empleo del excurso narrativo. Esta práctica no está vinculada exclusivamente al escritor vinarocense, pero todo parece indicar que él fue el primero que en sus novelas empezó a incluir el material ajeno a la ficción. Se sirve de los excursos literarios no solo como soporte ideológico y didáctico, sino que convierte las páginas de sus obras en una eficaz plataforma de publicidad a través de la cual anuncia sus propias novelas y las novelas del círculo de autores que publicaban sus obras en la editorial Sociedad literaria. Nuestras observaciones se centran en su famosa trilogía publicada María, la hija de un jornalero (1845), Marquesa de Bellaflor o el niño de la Inclusa (1846) y Palacio de los crímenes o El pueblo y sus opresores (1855).
\end{abstract}

Palabras clave: excurso narrativo, novela popular, Ayguals de Izco, autor implícito, material extraliterario.

${ }^{1}$ jovanovic.nena@gmail.com 


\section{Preliminares}

En este acercamiento a uno de los rasgos más notables de la narrativa del escritor vinarocense partimos de los planteamientos de Romero Tobar sobre los códigos narrativos que analiza en un corpus de veintinueve novelas populares, que se extiende de 1831 a 1867 , y de su noción de excursos, esto es detenciones novelescas o extranovelescas, que introduce para analizar "la llamativa presencia del autor" en el relato que se manifiesta "en el monólogo explicativo dirigido al lector, como cómplice de la trama novelesca y sus funciones simbólicas, o por medio más conocido de los comentarios y las explicaciones de la finalidad docente" (1976: 153-154).

Conscientemente evitando caer en la trampa de interpretaciones reduccionistas en este tipo de análisis, lo que supondría ver "modelos de estructuras que se repiten de un modo mecánico", Tobar (1976: 156) señala la voz del narrador omnipresente, omnipotente y omnisciente como un elemento constante y predominante en la producción novelesca del período investigado y en las novelas de Ayguals de Izco. Baulo (2004: 10) también afirma que esta "hipertrofia" de la presencia del narrador es uno de los rasgos en los que se funda la novela popular. En la trilogía novelesca de nuestro autor, en diferente medida están presentes las tres modalidades apuntadas por Tobar que utilizan los autores para dialogar con sus lectores: expresión directa de las intenciones del autor, excurso encubierto expresado por medio de algún personaje modélico y la última, reflexiones de autor sobre infinidad de temas que le preocupan. Sin embargo, interés especial ofrecen sus detenciones extranovelescas - la utilización del material ajeno a la ficción que intercala en el relato. Resulta imprescindible referirse aquí a la figura de Ayguals de Izco por partida doble: por el abundante uso y hasta abuso de esta técnica, y por la influencia que ha ejercido en un buen número de los escritores de la época. Gracias al éxito de sus novelas, la mayoría publicada en varias ediciones María o la hija de un jornalero (1845) tuvo hasta once ediciones y varias traducciones al francés, italiano, portugués y alemán, que salen a la luz muy poco tiempo después de la versión original, ${ }^{2}$ pero también debido

\footnotetext{
${ }^{2}$ Antonio Elorza (1997: n. 41) nos proporciona el dato de la primera edición en Francia, publicada por la "Librairie de Dutertre" en 1846, bajo el título Marie l'Espagnole, ou la victime d'un moine: histoire de Madrid, con una introducción de Eugenio Sue y los grabados de la edición española. La primera edición en italiano fue publicada en 1847 con el título Maria la spagnola, en Firenze por Giuseppe Celli. Las siguientes son: Livorno (1861), la Libreria romantica; Milano (1869-1870) por Giovanni Greco y hermanos Valsecchi;
} 
a la actividad de su casa editorial y sus estrategias muy adelantadas a su tiempo, su modo de novelar se convierte en el modelo a seguir. No es casual que confeccionando la muestra de las novelas populares para su análisis, Tobar incluya cinco títulos del escritor vinarocense, dejando aparte solo su primera novela Ernestina (1844) sobre la invasión de Sicilia por Enrique de Suavia en 1194, y la última, El palacio de los crímenes o el pueblo y sus opresores (1855), en la que predomina el plano histórico y lo novelesco como si fuera de interés secundario para el autor.

El profuso uso de los excursos y las frecuentes interrupciones de la narración con discursos de la más variada índole no han pasado desapercibidos entre los contemporáneos de Ayguals de Izco. Para la prensa de ideología conservadora este proceder es un grave defecto y un motivo más para despotricar de su obra. ${ }^{3}$ Zavala (1971: 270) recoge una valoración sumamente negativa, publicada en un extenso artículo del periódico La Censura en 1848, en el que se expone detalladamente una serie de defectos, "disparates" e "ideologías falsas", junto con el número de la página donde se encuentran, por los que la obra debería estar prohibida. ${ }^{4}$ El texto abre la crítica de la "desmesurada información sobre los espacios en los que se mueven sus personajes", y la abundancia de discursos históricos intercalados:

Habla, por ejemplo, de que tal o cual personaje de su novela bajó a pasear al Prado, pues a renglón seguido viene la descripción circunstanciada de este paseo, de quien le mandó construir y cuando, etc. Esto pudiera pasar una vez y respecto de un sitio que lo mereciera; lo hace con cuantos edificios, paseos, sitios reales y lugares salen a relucir en su narración.

Por otro lado, la prensa liberal se refiere a "los méritos literarios" de las novelas de Ayguals de Izco en términos laudatorios. En este sentido

Milano (1880) por Carlo Simonetti; Firenze (1888) por Salan. Recogido en L'almanacco bibliográfico (2007: 13). La edición portuguesa fue publicada como Maria a Filha de um Jornaleiro (1848-1849) y la alemana Maria die Spanierin, en 1847.

${ }^{3}$ Pascual Cataldi, amigo de Ayguals de Izco y director del periódico Correo de los teatros escribe el artículo titulado Escándalo (28-3-1852), una defensa de las obras del escritor vinarocense que "respiran la sana moral por todas partes", contra estas "censuras descompasadas" de los "nuevos alumnos de Torquemada". En la misma página está publicado el anuncio para el nuevo libro de Ayguals, La maravilla del siglo.

${ }^{4}$ Efectivamente, esta novela acabó en la lista de los libros prohibidos, Index Librorum Prohibitorum, el 6 de septiembre de 1852 (2002, V. XI: 94). El mencionado artículo de Pascual Cataldi de la nota anterior, fue la respuesta directa a la inclusión de la obra de Ayguals de Izco en la lista. 
es ilustrativo, aunque de objetividad cuestionable, el juicio de Antonio Ribot y Fontseré, publicado en El Telégrafo de Madrid, el 1 de septiembre de 1846, reproducido también en la biografía de Blas Araque (1850: 51-52), donde se justifica el uso de esta técnica tan presente en toda su producción novelesca con la intención docente:

\begin{abstract}
El señor Ayguals de Izco, como Sue y otros celebres novelistas, interrumpe con harta frecuencia el curso de la narración con reflexiones morales, políticas y religiosas, que lo mismo que las largas descripciones, mantienen al lector separado por demasiado tiempo del teatro en el que se desenvuelven las escenas, y que nosotros, que queremos que los efectos morales se desprendan exclusivamente de los efectos dramáticos, las consideraríamos superfluas, si no estuviésemos persuadidos de que la novela del señor Ayguals, como las de Sue y otros, están escritas para las clases trabajadoras que necesitan, por su falta de instrucción, que se le desmenucen mucho las ideas, para que su cerebro las pueda digerir.
\end{abstract}

El mismo Eugenio Sue ofrece un testimonio encomiástico sobre las dotes literarias del que fue el traductor y el mayor promotor de sus obras en España en la parte introductoria de la novela María o la hija de un jornalero. El controvertido escritor francés y modelo directo de Ayguals, valora positivamente la abundancia del material extraliterario y los continuos desplazamientos de los personajes. En su parecer, utilizando esta técnica Ayguals de Izco demuestra ser un "erudito historiador, sabio anticuario, crítico y apreciador elocuente de las obras maestras de la pintura y escultura, lo mismo que se ha mostrado antes, escritor fogoso, narrador sorprendente, publicista imparcial y convencido" (María, t. I: 10).

\title{
2. Historia y novela a partes iguales
}

Creemos oportuno recordar en líneas breves las ideas sobre la novela de Ayguals de Izco, ya que en buena medida arrojan luz sobre el uso desmesurado de los excursos. Con su historia-novela pretende paliar la ausencia de la novela nacional en una época cuando "entre ñoñeces y monstruosidades dormitaba la novela española" (Menéndez Pelayo 1897: 56), o como dice el propio escritor, "hallábase totalmente supeditada a la vergonzosa tutela de los extranjeros" y "detestables" traducciones (Marquesa, t. II: 508), aludiendo a la enorme penetración primero de la literatura inglesa, y luego de la francesa, para él especialmente dolorosa, dado que es de opinión como muchos otros escritores del momento 
que los "genios" españoles no tienen nada que envidiar a los franceses. Ayguals quiere marcar distancia con la novela histórica al uso en la que se reconstruyen los acontecimientos de las épocas lejanas porque para él la novela contemporánea debe centrarse en los sucesos y momentos significativos de la historia nacional reciente. ${ }^{5}$ La denominación historianovela implica la coexistencia de lo histórico y novelesco, de la ficción y lo documental en sus novelas, lo que el vinarocense, muy propenso a las justificaciones y explicaciones de sus técnicas y procedimientos, explica en la dedicatoria dirigida a Sue que abre la primera parte de la trilogía María o la hija de un jornalero. A pesar de ser este párrafo muchas veces citado, creemos que es pertinente reproducirlo nuevamente, ya que estas líneas resumen su intención de crear una novela de acuerdo con el mencionado esquema binario, que en parte podría traducirse en el antiguo principio horaciano "deleitar enseñando":

Yo creo que pudieran muy bien escribirse verdaderas y acabadas historias que detallasen por do quiera todo el interés, toda la poesía, toda la amenidad, todos los alicientes de la novela, con solo eslabonar hábilmente la fábula con la realidad, siempre instructiva y respetable, de manera que la parte de invención no perjudicase a la veracidad de los sucesos. (María, t. I: 7)

En el epílogo de la misma novela Ayguals por primera vez utiliza este membrete historia-novela, declarándose creador de un género nuevo y revela su intención de crear una novela "puramente española", basada en los principios de la verdad, en la que representaría de manera minuciosa y fiel todos los grandes sucesos ocurridos en Madrid durante el periodo del Estatuto Real. No obstante, la primera edición no lleva el subtítulo de historia-novela sino novela original, lo que cambiará en algunas ediciones posteriores. ${ }^{6}$ Vuelve al tema de la historia-novela en la última parte de su ciclo narrativo, El palacio de los crímenes o el pueblo y sus opresores, que por algún motivo, al contrario de la costumbre de la época, no lleva ningún subtítulo. El epílogo de esta obra, publicada una década después de la primera parte, contiene la exposición más completa de sus ideas sobre la novela y literatura. ${ }^{7}$ Su concepto sobre el género literario al que

\footnotetext{
${ }^{5}$ En este sentido muchos investigadores lo señalan como precursor del episodio nacional de Benito Pérez Galdós.

${ }^{6}$ Baulo (1995: 62n) afirma que este subtítulo aparece en la sexta edición de María (1849), a lo que añadimos que también se encuentra en la séptima que salió de la prensa el mismo año y la que hemos podido consultar.

${ }^{7}$ El texto está organizado en diez capítulos en los que trata los fundamentos de su idea
} 
se ha dedicado no cambia, más bien se asientan sus reflexiones que iba expresando a lo largo de los años en otras obras y textos periodísticos. No obstante, es evidente que estaba al tanto de las críticas y debates que suscitaba su producción novelesca, que se publicaban en los periódicos de la época, y aprovecha la ocasión para responder a lo que entiende como acusaciones y para defenderse. De este texto que se extiende en varias páginas aquí resumiremos solo lo que consideramos fundamental para el tema de nuestro trabajo. En primer lugar señalar los conceptos básicos de su estética: verdad, verosimilitud, sencillez, utilidad, virtud y sobre todo moralidad, un elemento obligado en su obra. De eso se desprende que la novela tiene que cumplir varias funciones: filosófica, histórica, política y moral a la par que divertir. El concepto de la verdad en su ideario a menudo tiene valor de la verdad ética o moral o aparece como sinónimo de la realidad, sin embargo no se trata de la verdad poética de la ficción, sino de "la verdad representativa" (Sebold 2007: 24). La verdad también se traduce en imparcialidad, de ahí tanta insistencia en la objetividad de la representación de todo de lo que habla, tanto lo bueno y agradable como lo malo y censurable. Por el gran respeto a la verdad acuña este término historia-novela y para marcar distancia con las novelas históricas clásicas. En su juicio, sin ese corpus de material histórico y extraliterario que introduce en sus novelas, su única función sería la de divertir, sin embargo, su obra es una historia-novela:

Como historia, ha debido encerrar en sus páginas, no solo los comprobantes de nuestras aseveraciones, sino los documentos oficiales de mayor interés y las graves acusaciones, que tanto los altos personajes, como el pueblo y la prensa periódica, han dirigido a los conculcadores de las leyes. De este modo no podrá decirse que hay en nuestras páginas exageración [...] y si nos acusan de haber escrito un libelo calumnioso, diremos que los españoles más ilustres en letras y armas, los políticos más eminentes, los patricios más probos, han sido nuestros cómplices y colaboradores, porque sus opiniones, sus discursos, sus mismas palabras están consignadas en nuestro libro [...]. (Palacio, t. II: 759)

El marco histórico y temporal de las novelas analizadas abarca el período desde 1834 hasta 1854, y los importantes acontecimientos históricos: la matanza de los frailes del 17 de julio de 1834, la jura de la Constitución por la Reina Gobernadora María Cristina de Borbón en

de novelar: La verdad, Crítica galante, Las bellas formas, Libertad, patria y bellas letras, El mal gusto, Las pasiones, Sencillez y verosimilitud, La virtud sobre todo, Percances inesperados, El porvenir. 
1836, la guerra carlista (1833-1839), la caída del ministerio presidido por Martínez de la Rosa (María o la hija de un jornalero); la proclamación de la Constitución de 1837, la abdicación de María Cristina en 1840, la regencia y la caída de Espartero, la vuelta a España de María Cristina ( $L a$ marquesa de Bellaflor); el levantamiento de Madrid del 2 de marzo y 7 de mayo de 1848, y el fusilamiento de trece conspiradores, el atentado contra la reina Isabel II el 2 de febrero de 1852. La revolución del 1854 conocida como Vicalvarada (El Palacio de los crímenes). Sin embargo, en su historia-novela el vinarocense informa a sus lectores no solo de los sucesos históricos y momentos importantes para la nación, sino también de realidades contemporáneas en general.

\section{Marco temático y vías de suministro de los excursos narrativos}

Dado que para agrupar los excursos temáticamente y definir la finalidad con la que se insertan habría que hacer una relación pormenorizada de todos los excursos que aparecen en la obra del escritor vinarocense, lo que nos llevaría fuera de los límites de este trabajo, hacemos referencia a los que destacan por su frecuencia y extensión. En este sentido son significativos los excursos geográficos 0 el tema madrileño, lo que en la obra de Ayguals de Izco es lo mismo, ya que la capital española es el escenario habitual de sus novelas mientras que la presencia de otras ciudades es esporádica. La abundancia de la información sobre la geografía urbana, espacios públicos y privados de Madrid, sus costumbres, gente que lo habita, ha sido uno de los temas más comentados entre los investigadores de literatura. El autor no se limita a las breves referencias y descripciones; aprovechando cualquier pretexto llena las páginas enteras de información sobre las calles, plazas, iglesias, teatros, museos, jardines, parques, puertas, paseos, casas privadas, diferentes instituciones y edificios públicos, fiestas, bailes populares, verbenas, comida, modas de vestir, hablar, vivir o el clima. El esquema habitual que utiliza se puede entrever ya en el Epílogo de su novela María o la hija de un jornalero. Un excurso largo sobre la iglesia de San Francisco el Grande abre la primera parte de la trilogía de la que nos ocupamos. Su función es introducir uno de los protagonistas y el principal personaje negativo de fray Patricio, que a su vez utilizará para lanzar el discurso anticlerical. Su posición ideológica se hace patente desde la primera frase:

[...] es curiosísimo el origen de este convento, suntuoso y magnífico, como solían ser todos los nidos de aquellos avechuchos con faldas, a quienes 
la ilustración del siglo lanzó de la sociedad, donde pretendían ejercer su despótico dominio, y en la cual parece tratan nuevamente de introducirse, para mengua de la civilización europea, seguramente con no menos santas intenciones de avasallar al pueblo y saciar en él su hidrópica sed de riquezas, de placeres y de venganzas. (María, t. I: 12)

A continuación se ofrece la leyenda de la fundación de la antigua iglesia y datos sobre la construcción de la nueva. Ayguals interrumpe el relato para relacionar el apellido de uno de los arquitectos, Sabatini, con las carretelas de Sabatini, y de ahí en plena descripción de la iglesia, pasa a hablar de estos coches curiosos que circulaban por las calles madrileñas, sirviendo de canalización, justo cuando los elegantes volvían de las tertulias y espectáculos públicos a sus casas. El escritor no deja que se le escape la oportunidad para criticar esta "vituperable costumbre" de Madrid y las autoridades por no hacer nada para resolver este problema, nada más que aplazar la hora de hacer acopio. En la segunda parte de la misma novela (t. II: 42) de nuevo se refiere a este asunto; en una nota al final de la página informa a los lectores que su crítica ha surgido efecto, porque la autoridad competente ha dispuesto que se haga una importante mejora: la construcción de las cloacas en la calle. Acabando este excurso, vuelve al anterior, describiendo el aspecto de la iglesia, su interior, los cuadros y demás lujos que lo adornan con lo que abre la puerta para introducir un nuevo discurso anticlerical, después del que por fin se da comienzo al texto novelesco con la entrada de la protagonista María y ya mencionado fray Patricio.

Los personajes de la trilogía están en constante movimiento y sus desplazamientos son el pretexto más habitual para volcar la información extraliteraria. Un paseo del marqués de Bellaflor con su amigo es la excusa suficiente para interrumpir sin más la ficción e exponer datos sobre la Plaza de Oriente y enumerar todas las estatuas ubicadas en este lugar (Marquesa, t. I: 314). De la misma manera Ayguals aprovecha una visita de María y su amiga baronesa al Museo de la pintura y escultura, hoy Prado, para presentar el museo, los cuadros exhibidos y la biografía de uno de sus pintores predilectos - Velázquez. Estas descripciones no se perciben como ornantes, no tienen nada que ver con la descripción literaria, son más parecidas al estilo periodístico, de ahí que su valor es puramente documental. Benítez (1979: 143) hasta cuestiona su autoría y plantea la posibilidad de que las escriben sus ayudantes siguiendo las indicaciones generales. La fuente a la que recurre con más frecuencia es Manual de Madrid. Descripción de la corte y de la villa (1831) de Mesonero 
Romanos. A veces introduce citas directas en el relato o en una nota al pie de la página, como es el caso de la información introducida sobre la cárcel Casa Galera (María, t. II: 353), proporcionando la página exacta de donde provienen, mientras otras veces solo indica que se funda en los datos que ha expuesto "cierto erudito y entendido escritor" (María, t. I: 219), como se refiere a Mesonero. A lo mejor el caso más llamativo representan los capítulos dedicados a San Lorenzo y La Granja, extensos excursos de más de treinta páginas, con los que Ayguals de Izco interrumpe la trama para ofrecer a los lectores distracción "de las melancólicas escenas de nuestro drama" y para "ensayar de cuanto haya notable" en cercanías de la capital (María, t. II: 170). En ellos el autor parte de la descripción minuciosa de la belleza y lujo de estos sitios, se fija en los jardines, estatuas y fuentes, y proporciona datos sobre los materiales de los que están construidos. En las notas al pie de página ofrece información sobre las deidades griegas y romanas cuyos nombres lleva la mayoría de las fuentes. Hasta añade un apéndice con "una exacta relación de las estatuas, figuras y demás ricos artefactos que se hallan en la galería baja del Real Palacio, con otras noticias tomadas de preciosos documentos y acreditados historiadores" (María, t. II: 231), en el que se enumeran las habitaciones de los palacios y hace el inventario de los adornos y cuadros que contienen, para que los lectores que no conocen este sitio tengan una idea más clara de sus riquezas. No se conforma con esto sino incluye también la tasación de las estatuas del jardín hechas en la testamentaria del rey Felipe V en 1748 donde figuran sus costos en reales de vellón y otra con los costos expresados en doblones de algunas fuentes y estatuas hechas en el período desde el 1 de septiembre de 1723 hasta finales de enero de 1733. Su verdadero propósito con todo esto es censurar el absolutismo y derroches de la monarquía, para demostrar "cuán costosos han sido siempre los reyes al pobre pueblo" (María, t. II: 206) que vive oprimido y en la penuria:

[...] si en vez de fabricar palacios y conventos se hubiesen invertido estas cantidades inmensas QUE SALEN SIEMPRE DEL SUDOR DE LAS MASAS POPULARES, en erigir por toda España grandiosos establecimientos de beneficencia pública, casas de corrección, colegios de enseñanza gratuita, espaciosas calzadas, puentes sólidos, caminos, canales, y cuanto contribuye a la prosperidad de las naciones, sin descuidar la organización de una escuadra respetable, que hiciese recobrar a la marina española su antigua preponderancia y esplendor. De este modo hubiera prosperado España [...] 
Las idas y venidas de los personajes además de ofrecer al escritor la posibilidad de incluir en el texto literario cualquier tipo de información relacionada con los lugares que visitan o transitan, también le abren campo para expresar directamente su intencionalidad, plasmar todo tipo de digresiones, ideológico-morales, políticas o sociales. Con el mismo fin aprovecha ciertas circunstancias o cualquier pormenor de la vida de sus personajes. Así mediante una conversación entre María y el negro Tomás, nacido en África, pero secuestrado y vendido como esclavo en la isla de Cuba, en la que este le relata su vida, Ayguals de Izco introduce el tema que realmente le interesa - el tráfico de negros, ya que el vinarocense es uno de los primeros escritores de su tiempo que habla sobre este tema y decididamente propaga la abolición de la esclavitud. Temiendo que sus lectores pudieran pensar que exageraba en la representación de las atrocidades cometidas en el comercio de los negros, copia varios párrafos publicados sobre este tema en el periódico El Fénix y los reproduce en el cuerpo del texto. Este procedimiento tan común en su narrativa lo utiliza para tratar sobre muchos otros temas sociales que aquejan su país como la mortalidad de los niños, el maltrato, la falta de educación, el hambre, la miseria económica y moral, los problemas laborales, el trato a los presos, el sistema judicial, siempre avalando sus dictámenes con una serie de documentos o textos no literarios. El tema de la pena capital, "el más feo borrón de esa encantada cultura de la moderna sociedad", lo saca a colación cuando Anselmo, el padre de la protagonista acaba en la cárcel, condenado a muerte (María, t. II: 164-169). Propugna su abolición dado que el fin del castigo debería ser corregir, no matar, porque matar significaría cometer un crimen para castigar otro. Por otro lado, cuando habla del tema de suicidio, pese a que levanta la voz contra este mal social, se muestra menos decidido e intenta justificar y disculpar este acto, al que en su opinión en general lleva la desesperación, padecimientos físicos y morales, no la locura. ${ }^{8}$ Para convencer a los lectores de la fuerza de sus argumentos se apoya en el médico y psiquiatra francés, Alexandre Jacques François Brière de Boismont (1797-1881) y en la autoridad de Voltaire, y reproduce fragmentos de sus obras. A la vez propone vías para su solución:

La miseria es indudablemente el más eficaz elemento de cuantos conducen el hombre al suicidio (...) creemos haber indicado en el curso de nuestra historia, los medios que tiene el gobierno ilustrado para moralizar el

\footnotetext{
${ }^{8}$ Irónicamente, su esposa Francisca de Gironella se suicidó en 1856, poco tiempo después de haber celebrado el veinte aniversario de bodas. Se desconocen los motivos por los se quitó la vida.
} 
pueblo. No se persiga la inocencia, no se deje en cruel abandono á los pobres artesanos. A los honrados jornaleros, protéjase la agricultura y el comercio aligerando los insoportables impuestos que les abruman, aliéntese las ciencias y las artes, prodíguese recompensas al mérito y á la virtud, y las artes, y desaparecerá de este modo la miseria, semillero de vicios y de crímenes, causa de la desesperación que conduce muchos infelices al suicidio. (María, t. I: 371)

Es sorprendente la variedad y la profusión del material ajeno a la ficción utilizado por Ayguals de Izco. Analizando la situación en la Inclusa - la casa de los niños expósitos (Marquesa, t. I: 156-157) acude a las estadísticas oficiales y reproduce los datos numéricos de los niños que han entrado en el orfanato, que se han salvado y los que han muerto en el período de 1837-1846, concluyendo con satisfacción que el número de los últimos ha disminuido significativamente. Este tipo de información, nada común para una novela, el autor la intercala directamente en el cuerpo de la novela. Simplemente interrumpe la trama, separa con un blanco la ficción del excurso, y luego retoma el relato en el punto donde lo ha dejado. Otras veces marca el inicio y el final de estas interrupciones de la narración mediante fórmulas como estas: "Suspendamos el relato a este efecto" (María, t. II: 205) y "Pero no turbemos el orden cronológico de nuestra historia" (Marquesa, t. I: 109). La inclusión de los textos no literarios es sobre todo característica de los excursos históricos que tienen mucho relieve en las novelas del escritor vinarocense, de acuerdo con su concepto de la novela. En las tres novelas se sirve del mismo esquema, sin embargo en la última parte de la trilogía, El palacio de los crímenes, lo histórico está en el primer plano hasta el punto de que la obra ya guarda pocas conexiones con la novela; lo novelesco casi parece pretexto para exponer el contenido histórico enlazado con numerosas interpretaciones de parte del autor de los sucesos presentados. A causa de la cantidad de los largos excursos engarzados, la trama se desarrolla de manera muy lenta, el desenlace es apresurado, y contrario de lo que se esperaría de Ayguals de Izco, no es satisfactorio ni provechoso para los protagonistas. La fuente más citada en las detenciones de carácter histórico en toda la trilogía es la obra Espartero. Historia de su vida militar y de los grandes sucesos contemporáneos (1846; 4 tomos), del liberal progresista, muy conocido en su tiempo, José Segundo Flórez. No hay nada peculiar en el hecho de que Ayguals de Izco se apoye en el texto del hombre con el que comparte la ideología y que además era amigo suyo, pero da la casualidad de que esta historia fue publicada en la famosa editorial del vinarocense, 
Sociedad literaria. De esta manera, citando los fragmentos de la obra en cuestión, justifica los juicios expuestos y a la vez promociona uno de los productos de su editorial. En menor medida acude a otra historia, El panorama de España. Crónica contemporánea (1842), obra de un grupo de liberales no nombrados. Para ilustrar, documentar o defender la posición tomada en las diferentes cuestiones que trata a menudo se sirve de los artículos de los periódicos, sobre todo los de la tendencia republicana y democrática, la prensa interesada en los problemas políticos y sociales: La Iberia, La Época, El Eco de Comercio, Las Novedades, Gaceta, El Diario español, El León español, El Constitucional, Soberanía nacional, El Heraldo, por mencionar algunos. El escritor no ve ningún inconveniente en incluir largos fragmentos de texto o el artículo entero en la novela, si esto sirve para sus propósitos. En su deseo de mostrar los negocios fraudulentos de la época y convencer a los lectores de la implicación en ellos del gobierno y de María Cristina, confecciona todo un capítulo Moderados pintados por sí mismos (Palacio, t. II: 226-250) de los "principales párrafos" del periódico clandestino Murciélago, en realidad extensos fragmentos de cuatro de los cinco números de esta publicación que salía de abril a junio de 1854, sin periodicidad fija, con el objetivo de destapar la corrupción imperante en la época, y a la que se atribuye el mérito de acelerar la revolución. Entre los materiales que incluye en su obra se encuentra gran cantidad de documentos dispares, discursos de los diputados (Rivero, Olozaga, O’Donnel), circulares de los ministros, decretos de las Cortes, proyectos de leyes o artículos del Código penal.

Por último, mencionar brevemente otra modalidad de los excursos presentes en la obra de nuestro escritor. Nos referimos a la mencionada práctica de incluir en la novela la publicidad tanto de sus obras como las de otros autores ${ }^{9}$ publicados en su casa editorial Sociedad literaria, la práctica que ha llevado a varios investigadores a considerarlo como el padre del marketing moderno en España. Una de las estrategias, menos obvia, es utilizar fragmentos de la obras o de los artículos de sus autores para apoyar o documentar los juicios que expone. Estos textos, siempre introducidos mediante algún comentario elogioso sobre la figura, erudición y calidad de la creación artística del autor en cuestión, proporcionado en el cuerpo de la novela o en una nota al pie de página. Mayor interés ofrece la publicidad directa que suele aparecer al final del libro, una novedad en la época, en la que aparte de la sinopsis de la novela

\footnotetext{
${ }^{9}$ Entre los autores vinculados con la casa editorial estaban: Víctor Balaguer, Manuel Bretón de los Herreros, Carolina Coronado, José Zorrilla, Pedro Mata, Juan de Capua, José Segundo Flórez, Alfonso García Tejero, su biógrafo Blas María Araque.
} 
se informa detalladamente a los lectores sobre el tipo de papel utilizado, cubiertas, grabados, precios de la entrega y del libro, puntos de venta y de suscripción en Madrid y en las provincias. Además, las novelas de esta casa editorial tenían su versión económica y de lujo, para estar al acceso de todo el mundo. En la edición de lujo de María, la hija de un jornalero de 1846, Ayguals dedica varias páginas (t. II: 198-210) a la actividad de la editorial, las obras publicadas e incluye los anuncios de hasta veintiocho obras de diferentes autores y la opinión de la prensa sobre sus novelas. No se limita el autor solo a la promoción de obras literarias, ${ }^{10}$ así en una nota encontramos un verdadero anuncio, parecido a los de hoy, del famoso sitio donde se reunían los liberales, La Fontana de oro, en el que elogia sus servicios, comodidades de las que dispone, tipo de clientes que lo frecuentan (María, t. I: 86). Este tipo de excursos prueba una vez más que el autor vinarocense no duda en incluir en sus novelas cualquier tipo de texto o información extraliteraria si esto sirve para sus intereses.

\section{Reflexiones finales a modo de conclusión}

Si se examinan detenidamente los pareceres de Ayguals de Izco sobre la novela, los que aparecen dispersos en sus voluminosas obras y aún más los recogidos en el famoso Epílogo de la última parte de su trilogía El palacio de los crímenes, se tiene la impresión de que tenía una idea muy clara de lo que debería ser una novela, o mejor dicho historianovela de la que se proclama creador. Habrá que reconocer que a lo largo de su trayectoria literaria era consecuente con su poética que en líneas generales se podría resumir en: aprovechar un argumento histórico para desarrollar una trama ficticia, presentar la realidad española que abarcaría la sociedad, la historia, la costumbre y la moral, respetando los principios de la verdad y verosimilitud, y luchar por el pueblo español. Muchos de los excursos que intercala en sus novelas se pueden explicar por ese afán de objetividad e verosimilitud. Si ampliamos este escueto resumen de su idea de la novela, se esclarecen un poco más los propósitos con los que escribe sus obras: pronunciar siempre la verdad, representar tanto las facetas positivas como las negativas de la sociedad para contribuir al triunfo de la moralidad y el progreso, cultivar un estilo sencillo pero no populachero o en sus palabras: "escribimos para que nos entienda todo el mundo" (Palacio, t. II: 752), escribir con el fin de provocar una reacción

\footnotetext{
${ }^{10}$ En Justicia divina o el hijo de deshonor (1859: t. II: 101-111) dedica diez páginas de su novela al anuncio de las pastillas de chocolate del doctor Tendyk, que elogia como un producto milagroso, útil y eficaz remedio para diferentes dolencias.
} 
del público, porque el mayor triunfo del escritor es "conmover a los demás excitando las pasiones" (Palacio, t. II: 757). Una de las funciones de los abundantes excursos geográficos es precisamente provocar la reacción de los lectores, crear la sensación de la realidad en ellos. Parece sincero el escritor en su intención de educar el pueblo, presentarle la verdad de los significativos sucesos de la historia reciente. Para no dejarle al público lugar a dudas en cuanto a la veracidad de lo expuesto, recurre a gran variedad de autoridades, toda clase de textos no literarios. Elije estos textos muy subjetivamente, de las fuentes heterogéneas, preocupándose de que el fragmento consignado a los temas que trata sea adecuado.

Este material extraliterario los críticos suelen considerarlo como material de relleno; sin embargo el argumento habitual de que los escritores de la época se servían de esta técnica para hinchar el volumen de sus obras, dado que cobraban por página escrita, difícilmente se podría aplicar a Ayguals de Izco. Pese a que no se puede negar que uno de los intereses que le movían a escribir era el económico, el vinarocense era un hombre de negocios muy hábil y propietario de la casa editorial que le permitía una vida desahogada y no le hacía falta recurrir a esta estrategia. Asimismo el discurrir paralelo de los dos planos: ficticio e histórico, la mayoría de los investigadores lo ha interpretado como la imposibilidad del autor de fusionarlos. Sin embargo, somos de la opinión que Ayguals de Izco utiliza este florilegio de documentos no literarios deliberadamente siguiendo los cánones de su propia poética. Es la posibilidad que señala Labany (2011: 96) en su análisis de la información madrileña en la novela María la hija de un jornalero, y que podría aplicarse a todos los excursos, que hay que considerarlos como parte integral del texto que corresponde al objetivo del escritor de presentarse como un historiógrafo fiel.

\section{FUENTES}

Ayguals de Izco, Wenceslao. María la hija de un jornalero. Historia-novela original. Madrid: Imprenta de Wenceslao Ayguals de Izco, 1845. Impreso.

Ayguals de Izco, Wenceslao. La marquesa de Bellaflor o el niño de la Inclusa. Historia-novela original. Madrid: Imprenta de Wenceslao Ayguals de Izco, 1847-1848. Impreso.

Ayguals de Izco, Wenceslao. El palacio de los crímenes o El pueblo y sus opresores. Madrid: Imprenta Ayguals de Izco Hermanos de Izco, 1855. Impreso. 


\section{BIBLIOGRAFÍA}

Araque, Blas María. "Biografía de don Wenceslao Ayguals de Izco". Pobres y ricos o la bruja de Madrid. Madrid: Imprenta de Wenceslao Ayguals de Izco, 1850: 1-40. Impreso.

Benítez, Rubén. Ideología del folletín español: W. Ayguals de Izco (18011873). Madrid: José Porrúa Turanzas, 1979. Impreso.

Baulo, Sylvie. "Novela popular y carlismo: Ayguals de Izco y la HistoriaNovela". Ignacio Arrellano \& Carlos Mata Induráin (Eds.). Príncipe de Viana. Congreso Internacional sobre la novela histórica. Homenaje a Navarro Villoslada, Pamplona, 1995: 59-69. Impreso.

Baulo, Sylvie. "La novela por entrega a mediados del siglo XIX: ¿Literatura al margen o del centro?". Ínsula, 693 (2004): 8-11. Impreso.

Calvo Carrillo, José Luis. "Las novelas de Ayguals de Izco". El sueño sostenible: estudios sobre la utopía literaria en España, Madrid: Marcial Pons, Ediciones de Historia, 2008: 105-151. Impreso.

Cataldi, Pascual. "Escándalo". Correo de los teatros. (28-03), Madrid: 1852. Web. 14 Feb. 2019.

Eco, Umberto. "Eugenio Sue: el socialismo y el consuelo". El superhombre de masas, México: DeBolsillo, 2007. Impreso.

Elorza, Antonio. "El tema de Francia en el primer republicanismo español". Jean-René Aymes \& Javier Fernández Sebastian (Eds.). L'image de la France en Espagne (1808-1850), Paris: Presses Sorbonne Nouvelle. 1997. Impreso.

Ferraz Martínez, Antonio. "Wenceslao Ayguals de Izco y la HistoriaNovela". La novela histórica contemporánea del siglo XIX anterior a Galdós, Madrid: Editorial de la Universidad Complutense de Madrid, t. I, 1992: 409-435. Impreso.

Index Librorum Prohibitorum. v. XI. J. M. Bujanda (Coord.). Montreal: Centre d’Études de la Renaissance. Universidad de Sherbrooke, 2002. Web. 14 Feb. 2019.

Karanović, Vladimir. Španska književnost realizma. Beograd: Filološki fakultet Univerziteta u Beogradu, 2018. Štampano.

Labanyi, Jo. "Being there: The Documentary Impulse from Ayguals de Izco to Galdós". Mark. A. Harpring (Ed.). Studies in Honor of Vernon Chamberlin, Newark: Juan de la Cuesta, 2011: 95-109. Print.

Menéndez Pelayo, Marcelino. Discurso de contestación al de ingreso de B. Pérez Galdós en la Real Academia Española, en 7 de febrero de 1897, Madrid, Vda. e Hijos de Tello, 1897. Web. 16 Feb. 2019. 
Miralles García, Enrique. "El bucle de la ficción y la historia en el ciclo narrativo de María o la hija de un jornalero, de W. Ayguals de Izco". Raquel Gutiérrez Sebastián \& Borja Rodríguez Gutiérrez (Coords.). 42 miradas en la literatura decimonónica. Individuo y sociedad, Santander: Trementorio ediciones, 2012: 309-320. Impreso.

Romero Tobar, Leonardo. La novela popular española del siglo XIX. Madrid: Ariel, 1979. Impreso.

Sebold, Russell P. En el principio del movimiento realista. Credoy novelística de Ayguals de Izco, Madrid: Ediciones Cátedra, 2007. Impreso.

Varela Olea, María Ángeles. "De la retórica a la erística en la industria editorial y en el folletín: María o la hija de un jornalero de Ayguals de Izco". Estudios Humanísticos. Filología, 36 (2014): 166-168. Web 15 Abr. 2018.

Zavala, Iris. M. Ideología y política en la novela española del siglo XIX, Salamanca: Anaya, 1971. Impreso.

\section{THE LITERARY FICTION AND EXTRA-LITERARY MATERIAL IN THE SPANISH POPULAR NOVEL: THE CASE OF AYGUALS DE IZCO}

\section{Summary}

The aim of this work is to address one of the predominant features of the hybrid novels of Ayguals de Izco: the extensive use of narrative excursus. This practice is not linked exclusively to the writer from Vinaros, but everything seems to indicate that he was the first who in his novels began to include non fictional material. He uses narrative excursus not only as ideological and didactic support, but converts the pages of his novels into an effective advertising platform through which announces the products of his publishing house Sociedad literaria, including his own novels. Our observations are based on his famous trilogy María, la hija de un jornalero (1845), Marquesa de Bellaflor o el niño de la Inclusa (1846) y Palacio de los crímenes o el pueblo y sus opresores (1855).

Keywords: narrative excursus, popular novel, Ayguals de Izco, implied author, extra-literary material. 